\title{
Sleep Quality and Associated Factors Among Type 2 Dm Patients and Non-Dm Individuals in Bahir Dar Governmental Hospitals: Comparative Cross- Sectional Study
}

Dagmawit Zewdu ( $\sim$ dagmawitzewdu4@gmail.com )

Bahir Dar University

Haileyesus Gedamu

Bahir Dar University

Yeshiwork Beyene

Bahir Dar University

Mekdes Tadesse

Bahir Dar University

Mahlet Tamirat

Bahir Dar University

Silenat Muluken

Bahir Dar University

\section{Research Article}

Keywords: Sleep quality, Type 2 DM, Non-DM, Ethiopia

Posted Date: December 28th, 2021

DOI: https://doi.org/10.21203/rs.3.rs-1189857/v1

License: (c) (i) This work is licensed under a Creative Commons Attribution 4.0 International License.

Read Full License 


\section{Abstract}

Background: Multiple factors may contribute to sleep disruption in type 2 diabetic individuals. Sleep disruption in type 2 diabetic individuals is frequently associated with long-term damage, dysfunction, and failure of different organs. Nevertheless, literature in this regard is scanty in Ethiopia. Therefore, this study aimed to assess and compare the prevalence of poor sleep quality and associated factors among type 2 diabetic and non-diabetic individuals in Bahir Dar governmental hospitals.

Methods: Comparative cross-sectional study was employed among 292 individuals with type 2 diabetes and 291 non-diabetic individuals in Bahir Dar governmental hospitals from March 01- to April-01. A twostage cluster sampling method was employed to select participants. Pittsburgh sleep quality index was used for assessing sleep quality. For analysis, descriptive and summary statistics were used to determine the prevalence and percentage of variables. Chi-square test was also used for comparison. Binary logistic regression analysis was employed to determine the associated factors of poor sleep quality.

Result: The prevalence of poor sleep was 50.7\% (95\% Cl; 44.9-56.2) and 31.8\% (95\% Cl 26.5-37.5) among individuals with type 2 diabetes and non-diabetic individuals respectively. Among the overall participants being type 2 diabetic patient was also found significantly associated with poor sleep quality as compared to non-diabetic individuals ( $A O R=1.89 ; 95 \% \mathrm{Cl} ; 1.19-2.87$ ). Comorbidity, duration of $\mathrm{DM}>10$ years, Poor glycaemic control, having depression, low physical activity, and poor social support were factors significantly associated with poor sleep quality among individuals with type 2 diabetes. Among nondiabetic individual's low physical activity, poor social support, having depression, and age group (>50 years) were factors significantly associated with poor sleep quality.

Conclusion: In this study, the prevalence of poor sleep among individuals with type 2 diabetes was higher than non-diabetes individuals.

\section{Introduction}

According to a simple behavioral definition, "sleep is a reversible behavioral state of perceptual disengagement and unresponsiveness to the environment". It is also a complex combination of physiologic and behavioral processes(1).

Sleep is also significant for the regulation of body temperature, immune defense, energy conservation, survival adaptation, removal of toxins generated during awake fullness, and facilitation of overall neuronal function(2).

Sleep problems are highly prevalent and include a reduction in quantity and quality of sleep. Several factors contribute to sleep disruption including lifestyle, environmental, psychosocial, sleep disorders, and medical conditions(3). Type $2 \mathrm{DM}$ is also linked with a higher prevalence of sleep disorders. Multiple factors may contribute to sleep disorder in type 2 diabetes patients including impaired glucose 
metabolism, nocturia, restless leg syndrome, depression, diabetic complications, and associated comorbidities with diabetes(4).

Sleep disruption had both short and long-term consequences which include increased stress responsivity, reduced quality of life (QoL), mental health problems, and other non-communicable diseases in healthy individuals $(3,5,6)$. Additionally, sleep disruption in individuals with type $2 \mathrm{DM}$ results in insulin resistance, and chronic hyperglycemia which is associated with long-term damage, dysfunction, and failure of different organs(7).

A study also shows the absolute mortality rate in adults with diabetes and longer sleep duration is also high(8). As a result, the US National Sleep Foundation works to make sleep a recognized "vital sign "for health(9). In USA the CDC also declared that insufficient sleep is a 'public health epidemic(10).

Studies across the world report poor sleep quality with a wide range of prevalence among type 2 diabetic individuals. In the USA more than half of individuals with diabetes (55\%) were "poor sleepers" according to the Pittsburgh Sleep Quality Index(11). The prevalence of poor sleep in the Asian continent range from 43.9-78.4\%, In Africa, the magnitude of poor sleep quality among type 2 DM patients ranges from $50 \%-97 \%(12,13)$. In Ethiopia, a study conducted in Jimma revealed that the prevalence of poor sleep quality among type 2 diabetes patients was $55.6 \%$ and $32.8 \%$ among relatively healthy individuals(14).

Concomitantly in recent decades, huge increases in diabetes prevalence have been shown in almost all regions of the world. The global diabetes prevalence in 2019 was 9.3\% (463 million people)(15). A review in Ethiopia shows that the prevalence of undiagnosed diabetes ranged from $2.0 \%-6.5 \%(16)$.

Nevertheless, literature on the occurrence of poor sleep quality among individuals with type 2 DM is not well documented. In general, we can fairly say that the association between DM and sleep quality and its magnitude in Ethiopia is not well established. Therefore, this study aims to assess and compare the sleep quality of type $2 \mathrm{DM}$ and non-DM individuals and identify its associated factors.

\section{Method And Materials}

\section{Study design and period}

Institutional based comparative cross-sectional study was conducted from March 01 to April 01.2021.

\section{Study Area}

This study was conducted in Bahir Dar the capital of Amhara national regional state in Ethiopia located approximately $578 \mathrm{~km}$ northwest of Addis Ababa. The city is located at the exit of the Abbay from Lake Tana at an altitude of 1,820 meters $(5,970 \mathrm{ft})$ above sea level. There are three governmental hospitals in the city these are, Felege Hiwot referral hospital, Tibebe Gihon specialized hospital, and Adiss Alem hospital. It's estimated that the total number of individuals with type $2 \mathrm{DM}$ in follow-up service in the three 
governmental hospitals is 6,500. On average approximately 650 individuals with type 2 DM are expected to come for follow-up within one month.

\section{Source of population}

The source population are all adult type 2 DM patients attending follow-up service in Bahir Dar governmental hospitals and the comparison groups are individuals who appear healthy in Bahir Dar governmental hospitals (patient accompanies in the medical OPD).

\section{Study population}

Type 2 DM patients who were attending follow-up service in Bahir Dar city selected governmental hospitals and available during the data collection period.

The comparison groups are non-DM individuals who appear healthy (patient accompanies in the medical OPD) in Bahir Dar selected governmental hospitals and available during the data collection period.

\section{Inclusion and Exclusion criteria}

Both type $2 \mathrm{DM}$ and non-DM individuals aged $\geq 30$ years were included in the study and individuals who were pregnant or lactating, seriously ill, and who had night-time shifts works were excluded.

\section{Sample size determination and sampling producer}

The sample size required for the first specific objective was calculated using Epi Info version 7.2 statistical software considering the proportion of poor sleep quality among individuals with type $2 \mathrm{DM}$ ( $P 1=55.6 \%)$ and comparison groups ( $P 2=33.3 \%$ ) from another similar study $(14)$. By using a 95\% confidence level and $80 \%$ power with the ratio of $1: 1$. This yields an initial sample size of 172 . By considering a $10 \%$ non-response rate, 189 is the total sample size.

The sample size for the second specific objective was calculated using the following assumptions; $\mathrm{Cl}=95 \%$, power $=80 \%$, the ratio of unexposed to exposed $=1 ; 1$, percent outcome in the exposed group (P1), and percent outcome in the unexposed group(P2) (Table 1).

Table 1. Sample size calculation 


\begin{tabular}{lllll} 
Independent variable & AOR & P1 & P2 & Sample size \\
\hline Female (17) & 2.5 & 87 & 73 & 278 \\
\hline Comorbidity (18) & 1.87 & 62.3 & 47 & 352 \\
\hline Glycaemic control (19) & 3.2 & 69 & 35 & 110
\end{tabular}

Accordingly, the sample size calculated by using the independent variable comorbidity was found to be the highest then after adding $10 \%$ non-response rate and 1.5 design effect 583 was taken as a final sample size for the study. Using 1; 1 ratio 291 diabetic individuals and 292 non-diabetic individuals.

Two-stage cluster sampling was used. The three study hospitals were considered as clusters then from the three clusters two hospitals (Felege Hiwot referral hospital and Tibebe Gihon specialized) were selected. Individuals with type 2 DM were selected using systematic random sampling. The sampling interval was determined by dividing the expected number of diabetic individuals who come to the hospitals within one month (550) by the sample size of cases (292) then it gives a sampling interval of two then individuals were selected every $2^{\text {nd }}$ unit. Non-DM individuals were also selected using a systematic random sampling technique. The expected number of patients accompanies in medical OPD within one month was 900 . The sampling interval was determined by dividing the expected number of patients accompanies in medical OPD who come to the hospitals within one month (900) by the sample size of the comparison group (291) so every $3^{\text {rd }}$ unit patient accompanies in OPD were interviewed.

\section{Operational definitions}

Sleep quality; The Pittsburgh Sleep Quality Index classifies a global score of $>5$ as indicating clients have poor sleeping quality, whereas a global score $\leq 5$ is classified as good sleeping quality(20).

Depression; A total score of PHQ-9 score $\geq 10$ points indicated major depression symptoms (21).

Social support; The Oslo social support index classifies a score of 3 to 8 as "poor support", $9-11$ is "moderate support" and 12-14 is "strong support"(22).

Current smoker; Someone who smoked greater than 100 cigarettes in their lifetime and had smoked in the last 28 days(23).

Alcohol consumption; Alcohol use disorder identification test (AUDIT) score $>8$ indicates hazardous alcohol consumption(24).

BMl; A person was classified as underweight $\left(\mathrm{BMI}<18.5 \mathrm{~kg} / \mathrm{m}^{2}\right.$ ), normal body weight (BMI 18.5-24.9 $\mathrm{kg} / \mathrm{m}^{2}$ ), overweight (BMI $\left.25-29.9 \mathrm{~kg} / \mathrm{m}^{2}\right)$, or obese $\left(\mathrm{BMI} \geq 30 \mathrm{~kg} / \mathrm{m}^{2}\right)(25)$. 
Good glycaemic control: A 3-month average fasting blood glucose measurement of the three consecutive visits was between 70 and $130 \mathrm{mg} / \mathrm{dL}(26)$.

Poor glycaemic control; Patients whose average fasting blood glucose measurements of the three consecutive visits was above 130 or below $70 \mathrm{mg} / \mathrm{dl}(26)$.

Comorbidity; a chronic disease that coexisted with their diabetes were considered to be comorbid(27).

\section{Data collection tools and instrument}

The English version questionnaire was translated into a local language Amharic. Three clinical nurses were recruited for data collection and one BSC nurse for supervision. The data collectors and the supervisor were trained for 2 days regarding the objective of the study and data collection procedure.

Structured questionnaires comprise Socio-demographic characteristics, a clinical characteristic checklist, sleep quality assessment, depression assessment, social support assessment, and physical activity assessment tool.

Using a digital glucometer, the blood glucose level of comparison group was assessed. The blood glucose result of RBS between 70 to 110 was considered as DM free.

Sleep quality was assessed using the Amharic version of PSQI. The PSQI comprises 19 self-rated questions that generate seven component scores (subscales). Each component scores $0-3$ points. A score of " 0 " is "no difficulty," while a score of " 3 " is "severe difficulty." The total scores of seven components are added to yield one "global score," which ranged from 0 to 21 points (20). It is validated in Ethiopia (Cronbach alpha of 0.6 ) (28). The reliability of the tool was tested by similar studies conducted in Ethiopia $(19,29)$.

Depression symptoms were assessed using the Patient Health Questionnaire-9 (PHQ-9). The PHQ-9 contains nine self-rated questions and the total scores ranged from 0 to 27 points(21). It is validated in Ethiopia with a Cronbach alpha of 0.81 (30).

Social support was assessed by using Oslo 3-item Social Support Questionnaire. The sum of the Oslo 3items social support score was ranged from 3 to 14 (22). It is also validated (22). The reliability of the tool is tested by another study conducted in Ethiopia(31).

The international physical activity questioners (IPAQ) were used to assess the physical exercise of participants. Using the IPAQ scoring protocol to considered participants into high, moderate, and low levels of physical activity categories(32). The reliability of the questioner tested by another study in Ethiopia(33).

Alcohol consumption was assessed using the alcohol use disorder identifier test (AUDIT). It is a 10-item questionnaire that covers the domains of alcohol consumption, drinking behavior, and alcohol-related 
problems(34). The AUDIT was also validated in Ethiopia (Cronbach's a = 0.84) (35).

BMI: participants were weighed in $\mathrm{kg}$ by using a digital weight scale in light clothing. Height was measured using a measuring tape; participants positioned their feet together, feet flat on the ground, with flat shoes, and it was recorded to the closer $0.5 \mathrm{~cm}$. Body mass index was calculated as the ratio of weight in kilograms to the square of height in meters.

\section{Data processing and analysis}

First, the data were checked for completeness then coded and entered using EPI-data version 3.1. The data were exported to Statistical Package for Social Science (SPSS) version 20 software for analysis. The data were then re-coded and cleaned. Multicollinearity was checked using variance inflation factor (VIF) and the VIF of each variable was $<5$. Model fitness was checked for the three models using the Homer-Lemeshow goodness of fit test and the $p$-value for all three models were $<0.05$. Descriptive and summary statistics were carried out to determine the prevalence and percentage of variables. Chi-square tests were also used for comparison. Bi-variable and multivariable logistic regression analyses were used to identify associated factors. Those variables with a p-value less than 0.25 in the bi-variable analysis were entered into the multivariable analysis. In multivariable logistic regression variables with a p-value, less than 0.05 with a $95 \%$ confidence interval were considered as significantly associated with outcome variables.

\section{Ethical approval and consent to participate}

The ethical approval was obtained from the institutional review board of Bahir Dar University, college of medicine, and health science. Written informed consent was taken from participants after the purpose of the study was clearly explained. Study participants have the right to withdraw from the study at any point in time. The information collected from the participants was used for research purposes only. To keep confidentiality, the collected information was kept in a file without a personal identifier of the study participant. Individuals with poor sleep quality and Participants that found to be at risk of depressive symptoms were referred to a psychiatric evaluation in the hospital. This study was conducted following the ethical standard of the declaration of Helsinki.

\section{Results}

\section{Socio-demographic characteristics}

A total of 575 participants were included in the study. Among them, 292 type 2 diabetic individuals with a response rate of $100 \%$ and 283 non-DM individuals with a response rate of $97 \%$. The mean age of individuals with type $2 \mathrm{DM}$ was 53.24 years (SD \pm 10.68 years) and that of non-DM individuals was 43.8 years (SD \pm 9.12 years). The majority, 233(79.8\%) of individuals with type 2 DM and 199(70.3\%) of non- 
DM individuals were from the urban area. Around 77 (26.4\%) of individuals with type 2 DM and $88(31.1 \%)$ of non-DM individuals attend diploma and above. More than half, 232 (79.5\%) of individuals with type 2 DM and 214 (75.6\%) of non-DM individuals were married (Table 2).

Table 2. Socio-demographic characteristics of individuals with type $2 \mathrm{DM}$ and non- DM individuals in Bahir dar city, Ethiopia, 2021 (575) 


\begin{tabular}{|c|c|c|c|c|c|}
\hline \multirow[t]{3}{*}{ Variables } & \multirow[t]{3}{*}{ Category } & \multicolumn{4}{|c|}{ Medical status } \\
\hline & & \multicolumn{2}{|c|}{ Non-DM } & \multicolumn{2}{|c|}{ Type 2 DM } \\
\hline & & Freq & Perc\% & Freq & Perc \% \\
\hline \multirow[t]{2}{*}{ Sex } & Male & 151 & 53 & 161 & 55.1 \\
\hline & Female & 132 & 46.6 & 131 & 44.9 \\
\hline \multirow[t]{3}{*}{ Age group } & $30-39$ & 116 & 41.0 & 37 & 12.7 \\
\hline & $40-49$ & 99 & 35.0 & 82 & 28.1 \\
\hline & $\geq 50$ & 68 & 24.0 & 173 & 59.2 \\
\hline \multirow[t]{5}{*}{ Education } & Diploma and above & 88 & 31.1 & 77 & 26.4 \\
\hline & Secondary & 53 & 18.7 & 60 & 20.5 \\
\hline & Primary & 51 & 18.0 & 56 & 19.2 \\
\hline & Read and write & 38 & 13.4 & 36 & 12.3 \\
\hline & Cannot read and write & 53 & 18.7 & 63 & 21.6 \\
\hline \multirow[t]{4}{*}{ Marital status } & Married & 214 & 75.6 & 232 & 79.5 \\
\hline & Single & 38 & 13.4 & 28 & 9.6 \\
\hline & Divorced & 22 & 7.8 & 13 & 4.5 \\
\hline & Widowed & 9 & 3.2 & 19 & 6.5 \\
\hline \multirow[t]{5}{*}{ Occupation } & Government employee & 101 & 35.7 & 86 & 29.5 \\
\hline & Farmer & 45 & 15.9 & 50 & 17.1 \\
\hline & Merchant & 44 & 15.5 & 55 & 18.8 \\
\hline & Housewife & 57 & 20.1 & 65 & 22.3 \\
\hline & Other & 36 & 12.7 & 36 & 12.3 \\
\hline \multirow[t]{2}{*}{ Residence } & Urban & 199 & 70.3 & 233 & 79.8 \\
\hline & Rural & 84 & 29.7 & 59 & 20.2 \\
\hline Income & Mean SD & 4436. & 2671.3 & 332 & \pm 2017.2 \\
\hline
\end{tabular}

Notes: Other *daily labor, Self-employed, 
About 93 (32.0\%) of individuals with type 2 DM and 61 (21.0\%) of non-DM individuals had depression. Regarding alcohol consumption 49(17.3\%) of non-DM and $19(6.6 \%)$ of individuals with type 2 DM had hazardous alcohol consumption. More than half of individuals with type 2 DM 157(53.8\%) and $130(45.9 \%)$ of non-DM individuals had perceived strong social support. Around half of the non-DM individuals, $139(49.3 \%)$ but less than half $124(41.5 \%)$ of individuals with type 2 DM had moderate physical activity (Table 3).

Table 3. Psychosocial and behavioral characteristics among individuals with type 2 DM and non-DM individuals Bahir dar city, Ethiopia, 2021. (575)

\begin{tabular}{|c|c|c|c|c|c|}
\hline \multirow[t]{3}{*}{ Variables } & \multirow[t]{3}{*}{ Category } & \multicolumn{4}{|c|}{ Medical status } \\
\hline & & \multicolumn{2}{|c|}{ Non-DM } & \multicolumn{2}{|c|}{ Type 2 DM } \\
\hline & & Freq & Perce \% & Freq & Perce $\%$ \\
\hline \multirow[t]{2}{*}{ Depression } & No & 222 & 78.4 & 199 & 68.2 \\
\hline & Yes & 61 & 21.6 & 93 & 31.8 \\
\hline \multirow[t]{3}{*}{ Social support } & Strong & 130 & 45.9 & 157 & 53.8 \\
\hline & Moderate & 78 & 27.6 & 76 & 26.0 \\
\hline & Poor & 75 & 26.5 & 59 & 20.2 \\
\hline \multirow[t]{3}{*}{ Physical activity } & Moderate & 139 & 49.3 & 124 & 42.5 \\
\hline & Vigorous & 46 & 16.3 & 51 & 17.5 \\
\hline & Inactive & 97 & 34.4 & 117 & 40.1 \\
\hline \multirow[t]{2}{*}{ Alcohol consumption } & Non-hazardous consumption & 234 & 82.7 & 273 & 93.5 \\
\hline & Hazardous consumption & 49 & 17.3 & 19 & 6.5 \\
\hline \multirow[t]{2}{*}{ Smoking } & No & 269 & 95.1 & 282 & 96.6 \\
\hline & Yes & 14 & 4.9 & 10 & 3.4 \\
\hline
\end{tabular}

Almost half of 143 (49.0\%) participants diagnosed type 2 DM within the last 5 years. Among individuals with type $2 \mathrm{DM}, 174$ (59.6.7\%) of the participants had a normal body mass index (BMI). The majority, 225 (77.3\%) of the participants used oral hypoglycaemic medication. More than half, 167 (57.2\%) of the participants had good fasting glycaemic control. Around $41 \%$ of individuals with type 2 DM had comorbidity (Table 4).

Table 4. Clinical characteristics of individuals with type 2 DM in Bahir dar, Ethiopia, 2021(292) 


\begin{tabular}{llrr} 
Variables & Category & Frequency & Percentage $\%$ \\
\hline BMI & $<=18.5 \mathrm{~kg} / \mathrm{m}^{2}$ & 5 & 1.7 \\
\hline & $18.5-25 \mathrm{~kg} / \mathrm{m}^{2}$ & 174 & 59.6 \\
\cline { 2 - 3 } & $\geq 25 \mathrm{~kg} / \mathrm{m}^{2}$ & 113 & 38.7 \\
\hline Glycemic control & Good & 167 & 57.2 \\
\hline \multirow{2}{*}{ Duration of DM } & Poor & 125 & 42.8 \\
\hline & $<5$ years & 143 & 49.0 \\
\hline Treatment modality & $5-10$ years & 84 & 28.8 \\
\cline { 2 - 4 } & $>10$ years & 65 & 22.3 \\
\hline Oral & Insulin & 222 & 76.0 \\
\cline { 2 - 4 } & Both & 49 & 16.8 \\
\hline Health Education & Attend education session & 200 & 7.2 \\
\hline Follow up & do not attend & 92 & 68.5 \\
\hline History of comorbidity & No & 214 & 31.5 \\
\hline & Yegular & 78 & 73.3 \\
\hline & Irregular & 171 & 26.7 \\
\hline & Nos & 121 & 58.6 \\
\hline
\end{tabular}

\section{Prevalence of sleep quality}

The prevalence of poor sleep quality among individuals with type 2 DM was $50.7 \%$ (95\% Cl; 44.9 $56.2)$; and $31.8 \%$ for non-DM individuals, $(95 \% \mathrm{Cl} 26.5-37.5)$ the mean (SD) GPSQ score was $6.84( \pm 4.2)$ for type 2 diabetic individuals and 4.45( \pm 3.0$)$ for non-DM individuals. Among participants, $43(14.7 \%)$ of individuals with type $2 \mathrm{DM}$ and $19(6.7 \%)$ of non-DM rated their overall sleep quality as bad and this difference was found to be significant. (Table 5).

Table 5. Components of PSQI among individuals with type 2 DM and Non-DM individuals Bahir dar city, Ethiopia, 2021 (575) 


\begin{tabular}{|c|c|c|c|c|c|c|c|}
\hline & & & & & Typ & $2 \mathrm{DM}$ & \\
\hline & & & & $\begin{array}{l}\text { Perce } \\
\%\end{array}$ & Freq & Perc\% & $\begin{array}{l}\text { Chi- } \\
\text { square }\end{array}$ \\
\hline $\begin{array}{l}\text { Subjective } \\
\text { sleep }\end{array}$ & Very good & & 192 & 68.1 & 124 & 42.6 & $X^{2=} 40.1$ \\
\hline Quality & & & & & & & $P=0.000$ \\
\hline & Fairly good & & 71 & 25.2 & 124 & 42.6 & \\
\hline & Fairly bad & 20 & & 6.7 & 44 & 14.8 & \\
\hline Sleep latency & $\begin{array}{l}<15 \\
\text { minutes }\end{array}$ & & 118 & 41.7 & 98 & 33.6 & $X^{2}=9.011$ \\
\hline & $\begin{array}{l}16-30 \\
\text { minutes }\end{array}$ & & 67 & 23.7 & 65 & 22.3 & $0.0 \angle 9$ \\
\hline & $\begin{array}{l}30-60 \\
\text { minutes }\end{array}$ & & 51 & 18.0 & 52 & 17.8 & \\
\hline & $\begin{array}{l}>60 \\
\text { minutes }\end{array}$ & & 47 & 16.6 & 77 & 26.4 & \\
\hline Sleep duration & $>7$ hours & & 90 & 31.8 & 94 & 32.2 & $x^{2=} 4.06$ \\
\hline & $6-7$ hours & & 115 & 40.6 & 103 & 35.3 & $P=1.67$ \\
\hline & 5-6 hours & & 65 & 23.0 & 69 & 23.6 & \\
\hline & $<5$ hours & & 13 & 4.6 & 26 & 8.9 & \\
\hline Sleep efficacy & $>85 \%$ & & 156 & 55.1 & 113 & 38.7 & $X^{2}=28.29$ \\
\hline & $75-84 \%$ & & 86 & 30.4 & 93 & 31.8 & $P=0.001$ \\
\hline & $65-74 \%$ & & 30 & 10.6 & 43 & 14.7 & \\
\hline & $<65 \%$ & & 11 & 3.9 & 43 & 14.7 & \\
\hline $\begin{array}{l}\text { Sleep } \\
\text { disturbance }\end{array}$ & Never & & 43 & 15.2 & 14 & 4.8 & $X^{2=} 57.21$ \\
\hline & $\begin{array}{l}\text { 1-times a } \\
\text { week }\end{array}$ & & 222 & 78.4 & 197 & 67.5 & \\
\hline & $\begin{array}{l}\text { 1-2 times a } \\
\text { week }\end{array}$ & & 18 & 6.4 & 82 & 27.7 & \\
\hline Use of sleep & never use & & 280 & 98.9 & 287 & 98.3 & $P=.72^{\star}$ \\
\hline & Use & & 3 & 1.1 & 5 & 1.7 & \\
\hline
\end{tabular}




\begin{tabular}{|c|c|c|c|c|c|c|}
\hline \multirow[t]{3}{*}{$\begin{array}{l}\text { Day time } \\
\text { dysfunction }\end{array}$} & $\begin{array}{l}\text { No } \\
\text { problem }\end{array}$ & 183 & 64.7 & 117 & 40.1 & \multirow{3}{*}{$\begin{array}{l}X^{2}=44.06 \\
P=0.000\end{array}$} \\
\hline & $\begin{array}{l}\text { 1-2 times a } \\
\text { week }\end{array}$ & 86 & 30.4 & 122 & 41.8 & \\
\hline & $\begin{array}{l}3 \text { times a } \\
\text { week }\end{array}$ & 14 & $4.9 \%$ & 53 & 18.2 & \\
\hline \multirow[t]{2}{*}{$\begin{array}{l}\text { Overall sleep } \\
\text { Quality }\end{array}$} & Good & 193 & $68.2 \%$ & 142 & $49.3 \%$ & \multirow{2}{*}{$\begin{array}{l}X^{2}=21.12 \\
P=0.000\end{array}$} \\
\hline & Poor & 90 & $31.8 \%$ & 150 & $50.7 \%$ & \\
\hline
\end{tabular}

Note: *=Fisher exact test

\section{Factors associated with poor sleep quality among the overall participants}

Those variables with a p-value less than 0.25 in the bi-variable logistic regression analysis were entered into multivariable logistic regression analysis. In multivariable logistic regression $p$-value $<0.05$ was considered significant.

Study participants with type 2 DM were 1.89 times more likely to have poor sleep quality than non-DM individuals (AOR=1.89 Cl; 1.19-2.87). Physical activity was also significantly associated with poor sleep quality among the overall participants. Those physically inactive participants were 3.89 times more likely to develop poor sleep than individuals with moderate physical activity ( $A O R=3.89 \mathrm{Cl} ; 2.47-6.14)$. In addition, study participants who had depression were 2.86 times ( $A O R=2.86 \mathrm{Cl} ; 1.81-4.53$ ) more likely to have poor sleep quality as compared to their counterparts. Moreover, Overall study participants who had poor social support were 4.4 times more likely to have poor sleep quality compared to participants who had strong social support $(\mathrm{AOR}=4.48 \mathrm{Cl} ; 2.63-7.62)$ (Table 6).

Table 6. Bi-variable and multi-variable logistic regression analysis on sleep quality among type $2 \mathrm{DM}$ and non-DM individuals (overall study participants) Bahir Dar city, Ethiopia 2021. 
Variables

Category

Sleep

quality

\begin{tabular}{|c|c|c|c|c|c|}
\hline & & Poor & Good & COR & AOR \\
\hline \multirow[t]{2}{*}{ Medical status } & Type 2 DM & 148 & 144 & $2.2(1.57-3.09)$ & $1.85(1.19-2.87)$ \\
\hline & Non-DM & 90 & 193 & 1 & 1 \\
\hline \multirow[t]{5}{*}{ Education } & $\begin{array}{l}\text { Cannot read and } \\
\text { write }\end{array}$ & 65 & 51 & $2.29(1.40-3.72)$ & $2.47)^{1.27(.65-}$ \\
\hline & Read and write & 37 & 37 & $1.79(1.03-3.13)$ & $1.09(.55-2.18)$ \\
\hline & Primary & 46 & 61 & $1.35(.82-2.22)$ & $.92(.50-1.68)$ \\
\hline & Secondary & 31 & 82 & $.67(.40-1.14)$ & $.56(.30-1.05)$ \\
\hline & Diploma and above & 59 & 106 & 1 & 1 \\
\hline \multirow[t]{4}{*}{ Marital status } & Single & 17 & 49 & $.48(.26-, 86)$ & $.50(.24-1.04)$ \\
\hline & Married & 187 & 259 & 1 & 1 \\
\hline & Divorced & 14 & 21 & $.92(.45-1.86)$ & $.57(.24-1.36)$ \\
\hline & Widowed & 20 & 8 & $3.46(1.49-8.03$ & $1.43(.53-3.85)$ \\
\hline \multirow[t]{3}{*}{$\begin{array}{l}\text { Physical } \\
\text { activity }\end{array}$} & Low & 129 & 85 & 4.81(3.24-7.14) & $3.89 \underset{\star \star}{(2.47-6.14)}$ \\
\hline & Moderate & 63 & 200 & 1 & 1 \\
\hline & High & 46 & 51 & $2.8(1.75-4.66)$ & $2.43(1.28-4.61)$ \\
\hline \multirow[t]{2}{*}{ Depression } & Yes & 99 & 55 & $3.65(2.47-5.37)$ & $2.86(1.81-4.53)$ \\
\hline & No & 139 & 282 & 1 & 1 \\
\hline \multirow[t]{3}{*}{ Age group } & $>50$ & 145 & 96 & $\begin{array}{l}3.98(2.58- \\
6.14)\end{array}$ & $1.95(1.10-3.43)$ \\
\hline & $40-50$ & 49 & 132 & $.92(.56-1.48)$ & $.73(.41-1.29)$ \\
\hline & $29-39$ & 44 & 109 & 1 & 1 \\
\hline \multirow[t]{3}{*}{ Social support } & Poor & 87 & 47 & $3.98(2.58-6.14)$ & $\underset{\star \star}{4.48(2.63-7.62)}$ \\
\hline & Moderate & 60 & 94 & $1.37(.91-2.06)$ & $1.33(.83-2.15)$ \\
\hline & Strong & 91 & 196 & 1 & 1 \\
\hline
\end{tabular}

Notes: *indicates statistically significant $(p<0.05)$, **highly statistically significant $(P<0.01)$. 


\section{Factors associated with poor sleep quality among non-DM individuals}

Those variables with a p-value less than 0.25 in the bi-variable logistic regression analysis were entered into multivariable logistic regression analysis. In multivariable logistic regression p-value $<0.05$ was considered significant.

Study participants who had poor social support were 2.83 times more likely to have poor sleep quality compared to participants who had strong social support (AOR=2.83; 95\% Cl: 2.83-13.65). Moreover, the physical activity of the study participants was a significant predictor variable for poor sleep quality. Those physically inactive participants were 3.17 times more likely to develop poor sleep than individuals with moderate physical activity (AOR=3.17; $95 \% \mathrm{Cl}: 1.59-6.29)$. In addition, study participants who had depression were 2.26 times ( $\mathrm{AOR}=2.26 ; 95 \% \mathrm{Cl}$ : $1.11-4.60)$ more likely to have poor sleep quality as compared to their counterparts. Moreover, those study participants who were in the age group ( $>50$ years) were 4.08 times more likely to have poor sleep than the younger age group ( $\mathrm{AOR}=4.08 ; 95 \% \mathrm{Cl}: 1.76-9.43)$ (Table 7).

Table 7.Bi-variable and multi-variable logistic regression analysis on sleep quality among non-DM individuals in Bahir Dar city, Ethiopia, 2021 (283) 
Variables

Category Overall sleep quality

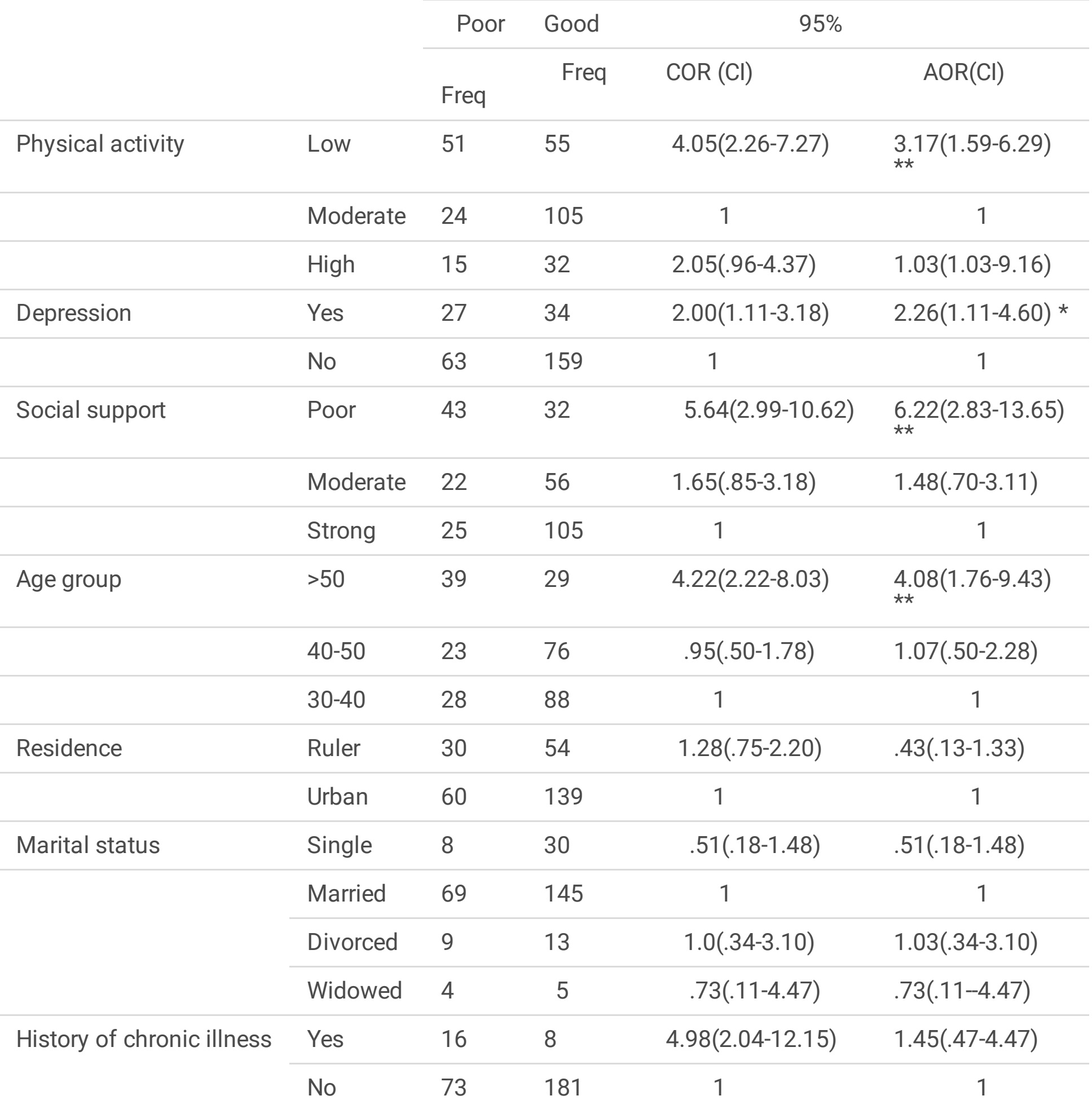

Notes: *indicates statistically significant $(p<0.05), * \star$ highly statistically significant $(\mathrm{P}<0.01)$.

Abbreviations: AOR: adjusted odds ratio, COR: crude odds ratio, $\mathrm{Cl}$ : confidence interval 


\section{Factors associated with poor sleep quality among individuals with type $2 \mathrm{DM}$.}

Those variables with a p-value less than 0.25 in the bi-variable logistic regression analysis were entered into multivariable logistic regression analysis. In multivariable logistic regression $p$-value $<0.05$ was considered significant.

Study participants with comorbidity were 2.21 times more likely to have poor sleep quality compared to participants without comorbidity ( $\mathrm{OOR}=2.21 ; 95 \% \mathrm{Cl}$ : 1.154-4.273). Moreover, Individuals with DM duration greater than 10 years were 3 times more likely to have poor sleep than individuals with a short duration of DM ( $<5$ years) (AOR $=3.0$ [95\% Cl: 1.28-7.04]). In addition, study participants who had depression were 2.6 times ( $\mathrm{AOR}=2.6 ; 95 \% \mathrm{Cl}: 1.29-5.54)$ more likely to have poor sleep quality as compared to their counterparts. Participants who are inactive or had low physical activity were 4.13 times more likely to have poor sleep quality as compared to those who had moderate physical activity (AOR= 4.13; 95\% Cl: $2.01-8.57)$.

Similarly, individuals with poor glycaemic control were 2.98 times (AOR $=2.98,95 \% \mathrm{Cl}: 1.53-5.79)$ more likely to have poor sleep quality as compared with individuals with good glycaemic control. And study participants who had poor social support were 2.25 times more likely to have poor sleep than individuals with strong social support (AOR=2.25,95\%Cl: 1.941-5.41) (Table 8).

Table 8.Bi-variable and multi-variable logistic regression analysis on sleep quality among individuals with type 2 DM Bahir dar, Ethiopia, 2021 
Variables

Category

Sleep Quality

$95 \% \mathrm{Cl}$

\begin{tabular}{|c|c|c|c|c|c|}
\hline & & & & & \\
\hline & & Poor & Good & & \\
\hline & & Freq & Freq & COR & AOR \\
\hline Education & $\begin{array}{l}\text { Cannot read and } \\
\text { write }\end{array}$ & 47 & 16 & $\begin{array}{l}4.13(1.99- \\
8.53)\end{array}$ & $8.09)^{2.83(.99-}$ \\
\hline & Read and write & 22 & 14 & $2.21(.98-4.96)$ & $1.52(.52-4.44)$ \\
\hline & Primary & 26 & 30 & $1.21(.60-2.43)$ & $\begin{array}{l}1.02(.39- \\
2.63)\end{array}$ \\
\hline & Secondary & 21 & 39 & $.75(.37-1.52)$ & $.95(.38-2.38)$ \\
\hline & $\begin{array}{l}\text { Diploma and } \\
\text { above }\end{array}$ & 32 & 45 & 1 & 1 \\
\hline Marital status & Single & 9 & 19 & $1.05)^{.458(.19-}$ & $.40(.13-1.25)$ \\
\hline & Married & 118 & 114 & 1 & 1 \\
\hline & Divorced & 5 & 8 & $.60(.19-1.90)$ & $.52(.12-2.18)$ \\
\hline & Widowed & 16 & 3 & $5.15(1.4-18.15)$ & $3.21(.74-13.9)$ \\
\hline Depression & Yes & 73 & 21 & $5.50(3.13-9.67)$ & $2.68(1.29-5.54)$ \\
\hline & No & 76 & 122 & 1 & 1 \\
\hline Smoking & Yes & 6 & 5 & $1.46(.40-5.31)$ & $1.18(.18-7.43)$ \\
\hline & No & 142 & 139 & 1 & 1 \\
\hline Comorbidity & Yes & 76 & 45 & $3.74)^{2.32(1.44-}$ & $\underset{*}{2.22(1.15-4.27)}$ \\
\hline & No & 72 & 99 & 1 & 1 \\
\hline $\begin{array}{l}\text { Glycemic } \\
\text { control }\end{array}$ & Poor & 96 & 29 & 7.32(4.31-12.42) & $\underset{\star \star}{2.98}(1.53-5.79)$ \\
\hline & Good & 52 & 115 & 1 & 1 \\
\hline $\begin{array}{l}\text { Duration of } \\
\text { DM }\end{array}$ & $>10$ years & 49 & 16 & $1.03)^{5.69(2.94-}$ & $\begin{array}{l}3.00(1.28- \\
7.04) \text { * }\end{array}$ \\
\hline & $5-10$ years & 49 & 35 & $4.52)^{2.60(1.49-}$ & $1.14(.53-2.43)$ \\
\hline & $<5$ years & 50 & 93 & 1 & 1 \\
\hline Age group & $>=50$ & 106 & 67 & 1.97(.95- & $.74(.27-2.02)$ \\
\hline & & & $8 / 28$ & & \\
\hline
\end{tabular}


4.08)

\begin{tabular}{|c|c|c|c|c|c|}
\hline & $40-50$ & 26 & 56 & $1.29)^{.58(.25-}$ & $.42(.15-1.26)$ \\
\hline & $30-40$ & 16 & 20 & 1 & 1 \\
\hline \multirow[t]{3}{*}{$\begin{array}{l}\text { Social } \\
\text { support }\end{array}$} & Poor & 44 & 15 & $7.87)^{4.04(2.07-}$ & $2.25(1.94-5.41)$ \\
\hline & Moderate & 38 & 38 & $1.37(.79-2.39)$ & $1.38(.67-2.87)$ \\
\hline & Strong & 66 & 91 & 1 & 1 \\
\hline \multirow[t]{3}{*}{$\begin{array}{l}\text { Physical } \\
\text { activity }\end{array}$} & Low & 83 & 34 & ${ }_{11.32)}^{6.46(3.68-}$ & $\underset{\star \star}{4.13(2.01-8.57)}$ \\
\hline & Moderate & 34 & 90 & 1 & 1 \\
\hline & High & 31 & 20 & $8.13)^{4.10(2.06-}$ & $2.41(.94-6.17)$ \\
\hline
\end{tabular}

Medical status $=\mathrm{DM}$

Notes: *indicates statistically significant $(p<0.05)$, **highly statistically significant $(P<0.01)$.

Abbreviations: AOR: adjusted odds ratio, COR: crude odds ratio, $\mathrm{Cl}$ : confidence interval

\section{Discussion}

The current study compared the sleep quality of individuals living with diagnosed type 2DM and attending DM follow-up clinic and non-DM individuals in Bahir Dar governmental hospitals. The prevalence of poor sleep quality among individuals with type $2 \mathrm{DM}$ was $50.7 \%$, (95\% Cl; 44.9-56.2); whereas $31.8 \%$ for non-DM individuals, (95\% Cl; 26.5-37.5).

The prevalence of poor sleep quality among individuals with type 2DM in this study is comparable with the previous studies conducted in Canada(52\%),(36) Brazilin (52\%),(37)Mayamr (48.4\%),(38) Kenya (53\%), (12) Gondar (47.2\%),(39) and Jimma (55.2\%) (19).

In contrast, the finding of the study is lower than the studies conducted in India (78.4\%)(40), Turkey(86.3\%) (41). Trinda Tobago (63.9\%),(42)and Saudi (72\%) (43). The possible reasons for the difference in these studies might be due to the use of different cut points. In addition, this might be also in Turkey the study participants were hospital-admitted DM patients. In India, around $60 \%$ of participants had co-morbidity and in Trinda Tobago the sleep quality was assessed by different assessment tools.

In this study, the prevalence of poor sleep quality among non-DM individuals was found $31.8 \%$. This finding is similar with a study in Jimma (32.3\%),(19) Kenya(29.5\%),(12) and Sudan(33.3\%) (13). 
This study reveals that among the overall participants there is a statistically significant association between being a type $2 \mathrm{DM}$ patient and poor sleep quality. This might be due to the Reduction of REM sleep latency arising from activation of the hypothalamic-pituitary-adrenal axis. Because individuals with type 2 DM are reported to exhibit an increase of HPA axis through poor glycemic control this mechanism might be involved in the reduction of REM sleep latency. The reduction in deep sleep might reflect decreased REM sleep latency in individuals with type 2 DM (44).

In a multivariable logistic regression analysis duration of DM was significantly associated with poor sleep quality. This finding agrees with findings in India,(18) Saudi,(45)Iran,(46)Brazil,(47) and Ethiopia Jimma (19). This might be due to the reason Patients with all forms of diabetes of long duration, are vulnerable to complications, which cause serious morbidity and lead to sleep disruption (48).

Depression was also significantly associated with poor sleep among individuals with type 2 DM and NonDM individuals. The finding was in argument with the study in England, (49)Maynmar,(38) China, (50) Africa,(51)and Gondar (39). This might be attributed to the reason in depressive patients, sleep complaints (eg insomnia, narcolepsy, sleep-disordered breathing, and restless legs syndrome are common in approximately $90 \%$ of patients (52). Insomnia is one of the typical and most dependable early symptoms of depression. Depression usually presents with physical symptoms, primarily fatigue, pain, or sleep disturbance (53). For diabetic individuals this might be also due to clinically significant depression, results from biochemical changes directly due to type 2 diabetes or its treatment, and the psychosocial demands caused by the illness (54). There is also an evidence that depression among individuals with type 2 diabetes is associated with poor diabetes outcomes such as glycaemic control and found that depression was significantly associated with poor glycaemic control in individuals with type 2 diabetes (55).

Being physically inactive or had low physical activity has been identified as one of the associated factors for poor sleep quality in both groups. This finding is in agreement with the finding in Europe (56). This could be due to the reason that moderate resistance training and stretching exercises are beneficial to people with insomnia. Fewer waking episodes during the night has also the benefit of long sleep duration, more sleep efficiency, and less overall anxiety (57). Additionally, for individuals with type 2 DM, this could also be because Physical exercise improves blood sugar control, the body's reaction to insulin, and decreased blood lipids (58). On top of that physical exercise had a crucial role in mood elevation which in turn improves sleep quality (59).

Moreover, Poor Glycaemic control was also significantly associated with poor sleep quality among individuals with type $2 \mathrm{DM}$. This finding was in line with a study in Japan,(60) Jordan,(61)Indonesia,(62), and Gondar (39).This might be due to the reason rapid changes in blood glucose levels during the night leading to hypoglycaemic and hyperglycaemic episodes and nocturia. Also, poor glycaemic control for a long duration leads to restless leg syndrome and diabetic complications (10).

Similarly, in this study having poor social support was found to be associated with poor sleep quality for both study groups. This is in line with the finding in the USA $(63,64)$ and Maymar $(38)$. This could be 
attributed to a direct, significant relationship between perceived social support and mental health (65).Social support provides physical and psychological advantages for people challenged with stressful physical and psychosocial events and is considered as a factor reducing the psychological distress when faced with stressful events (66).Social support tends to matter for psychological distress and depression independent of stress level (67).

Comorbidity was also significantly associated with poor sleep quality among individuals with type 2 DM. This finding is consistent with the study in India (18) and Gondar (39). This might be due to disturbed sleep is likely a disruptive symptom and outcome of many co-morbid medical conditions, and it may be an illness that individuals face as a side-effect of treatment for their illness. Pain due to the illness can also disturb one's sleep, and similarly, disturbed sleep may increase pain (68).

\section{Limitation of the study}

This study uses a subjective sleep quality assessment tool it doesn't use a sleep diary and objective sleep quality assessment tools. The limitation of the study is related to the cross-sectional nature of the study, which makes it difficult to find whether the exposure precedes the outcome.

\section{Conclusion}

In this study, the prevalence of poor sleep among individuals with type $2 \mathrm{DM}$ is higher than non-DM individuals. Among overall participants being type $2 \mathrm{DM}$ patient has a significant association with poor sleep quality as compared to non-DM individuals. Variables such as poor glycaemic control, comorbidity, longer duration in DM (>10 years), having depression, poor social support, and having low physical activity were found to be associated with poor sleep quality among individuals with type $2 \mathrm{DM}$. For nonDM participant's low physical activity, poor social support, having depression, and older age was associated with poor sleep quality. Promoting social support at any aspect of health care service is important to minimize poor sleep quality. Individuals with type 2 DM need to control their blood glucose to improve their sleep quality. Additionally, regular physical exercise is needed to prevent poor sleep quality.

\section{Abbreviations}

BMI: Body Mass Index

CDC: Centre for Disease Control and Prevention

DM: Diabetes Mellitus

FPG: Fasting Plasma Glucose Level

HbA1c: Glycrated Haemoglobin 
HPA: Hypothalamic-Pituitary-Adrenal Axis

IPAQ: International Physical Activity Questionnaire

MDD: Major Depressive Disorder

OSA: Obstructive Sleep Apnea

PHQ-9: Patient Health Questionnaire

PSQI: Pittsburgh Sleep Quality Questionnaire index

QoL: Quality of Life

REM: Random Eye Movement

SD: Sleep Disorder

T2DM: Type 2 Diabetes Mellitus

\section{Declarations}

\section{Ethical approval and consent to participants}

Ethical approval was obtained from Ethical Review Committee of Bahir Dar University. Written consent was taken from the participants for their voluntary participation. Confidentiality was maintained throughout the study process.

\section{Consent for publication}

Not applicable

\section{Availability of the data}

The data used to support the findings of this study are available from one of the corresponding authors on rational request.

\section{Competing interest}

The authorsdeclare that there is no any competing interest.

\section{Funding}

The source of funding for the current research is from Bahir Dar University College of medicine and other health science. The funder had no role in the design, data collection, analysis, drafting, manuscript, preparation, and publication of this paper. 


\section{Author information}

\section{Affiliation}

Department of Adult Health, College of medicine and health science, Bahir Dar University, Bahir Dar, Ethiopia

Dagmawit Zewdu, Haileyesus Gedamu, and Yeshiwork Beyene

Department of pediatric and child health, College of medicine and health science, Bahir Dar University, Bahir Dar, Ethiopia

Mahlet Tamirat, Slenat Muluken, and Mekdes Tadesse

\section{Contributions}

Dagmawit Zewdu (dagmawitzewdu4@gmail.com) organized the original investigation; coordinated the collection of data; analysis and writing report. Haileyesus Gedamu (haileyesusg5@gmail.com) Yeshiwork Beyene (dagmawit2005natnael@gmail.com) contributed to the supervision in design of the study and statistical analyses, Mahlet Tamirat (mahlettamirat7@gmail.com), Mekdes Tadesse (mekdestadesse88@yahoo.com), and Slenat Muluken (silemuluken@gmail.com) contributed to the drafted and revision of the Manuscript. All authors read and approved the final manuscript.

\section{Corresponding author}

Correspondence to: Dagmawit Zewdu Email address: dagmawitzewdu4@gmail.com

\section{Acknowledgment}

We would like to acknowledge Bahir Dar University, department of adult health nursing college of medicine and health science, for the opportunity and financial aid. We are very much indebted to Bahir Dar Governmental hospital OPD managers and staff members for their support during data collection. Finally, we would like also to extend our special thanks to the study population for their willingness, support, and time.

\section{References}

1. Carskadon MA, Dement WC. Normal human sleep: an overview. Principles and practice of sleep medicine. 2005;4:13-23.

2. Aldrich MS. Sleep medicine: Oxford University Press; 1999.

3. Medic G, Wille M, Hemels ME. Short-and long-term health consequences of sleep disruption. Nature and science of sleep. 2017;9:151. 
4. Khandelwal D, Dutta D, Chittawar S, Kalra S. Sleep disorders in type 2 diabetes. Indian journal of endocrinology and metabolism. 2017;21(5):758.

5. Matricciani L, Bin YS, Lallukka T, Kronholm E, Wake M, Paquet C, et al. Rethinking the sleep-health link. Sleep health. 2018;4(4):339-48.

6. Chokroverty S. Overview of sleep \& sleep disorders. Indian J Med Res. 2010;131(2):126-40.

7. AlDabal L, BaHammam AS. Metabolic, endocrine, and immune consequences of sleep deprivation. The open respiratory medicine journal. 2011;5:31.

8. Wang Y, Huang W, O'Neil A, Lan Y, Aune D, Wang W, et al. Association between sleep duration and mortality risk among adults with type 2 diabetes: a prospective cohort study. Diabetologia. 2020;63(11):2292-304.

9. Ojile J. National Sleep Foundation sets the standard for sleep as a vital sign of health. Sleep Health: Journal of the National Sleep Foundation. 2017;3(4):226.

10. Liu Y, Wheaton AG, Chapman DP, Cunningham TJ, Lu H, Croft JB. Prevalence of healthy sleep duration among adults-United States, 2014. Morbidity and Mortality Weekly Report. 2016;65(6):13741.

11. Luyster FS, Dunbar-Jacob J. Sleep quality and quality of life in adults with type 2 diabetes. The diabetes educator. 2011;37(3):347-55.

12. Sokwalla SMR, Joshi MD, Amayo EO, Acharya K, Mecha JO, Mutai KK. Quality of sleep and risk for obstructive sleep apnoea in ambulant individuals with type 2 diabetes mellitus at a tertiary referral hospital in Kenya: a cross-sectional, comparative study. BMC endocrine disorders. 2017;17(1):1-8.

13. Mirghani H. Sleep quality effects on glycemic control among Sudanese patients with type 2 diabetes -a case-control study. Basic Res J Med Clin Sci. 2015;4:258-61.

14. Jemere T, Mossie A, Berhanu H, Yeshaw Y. Poor sleep quality and its predictors among type 2 diabetes mellitus patients attending Jimma University Medical Center, Jimma, Ethiopia. BMC Research Notes. 2019;12(1):488.

15. Saeedi P, Petersohn I, Salpea P, Malanda B, Karuranga S, Unwin N, et al. Global and regional diabetes prevalence estimates for 2019 and projections for 2030 and 2045: Results from the International Diabetes Federation Diabetes Atlas. Diabetes research and clinical practice. 2019;157:107843.

16. Bishu KG, Jenkins C, Yebyo HG, Atsbha M, Wubayehu T, Gebregziabher M. Diabetes in Ethiopia: a systematic review of prevalence, risk factors, complications, and cost. Obesity Medicine. 2019;15:100132.

17. Barakat S, Abujbara M, Banimustafa R, Batieha A, Ajlouni K. Sleep quality in patients with type 2 diabetes mellitus. Journal of clinical medicine research. 2019;11(4):261.

18. Gara H, Panda K, Vanamali D. Subjective Sleep Quality in Type-2 Diabetics. Indian J Physiol Pharmacol. 2019;63(2):155-9.

19. Jemere T, Mossie A, Berhanu H, Yeshaw Y. Poor sleep quality and its predictors among type 2 diabetes mellitus patients attending Jimma University Medical Center, Jimma, Ethiopia. BMC 
research notes. 2019;12(1):1-6.

20. Buysse DJ, Reynolds III CF, Monk TH, Berman SR, Kupfer DJ. The Pittsburgh Sleep Quality Index: a new instrument for psychiatric practice and research. Psychiatry research. 1989;28(2):193-213.

21. Kroenke K, Spitzer RL, Williams JB. The PHQ-9: validity of a brief depression severity measure. Journal of general internal medicine. 2001;16(9):606-13.

22. Abiola T, Udofia O, Zakari M. Psychometric properties of the 3-item oslo social support scale among clinical students of Bayero University Kano, Nigeria. Malaysian Journal of Psychiatry. 2013;22(2):3241.

23. Sahile AT, Bekele GE. Prevalence of Diabetes Mellitus and Associated Factors in Addis Ababa Public Health Facilities, Addis Ababa, Ethiopia, 2016. Diabetes, metabolic syndrome and obesity: targets and therapy. 2020;13:501.

24. Babor TF, De La Fuente JR, Saunders J, Grant M. Guidelines for use in primary health care. 1992.

25. Weir CB, Jan A. BMI classification percentile and cut off points. 2019.

26. Demoz GT, Gebremariam A, Yifter H, Alebachew M, Niriayo YL, Gebreslassie G, et al. Predictors of poor glycemic control among patients with type 2 diabetes on follow-up care at a tertiary healthcare setting in Ethiopia. BMC research notes. 2019;12(1):207.

27. Pantalone KM, Hobbs TM, Wells BJ, Kong SX, Kattan MW, Bouchard J, et al. Clinical characteristics, complications, comorbidities and treatment patterns among patients with type 2 diabetes mellitus in a large integrated health system. BMJ Open Diabetes Research and Care. 2015;3(1).

28. Salahuddin M, Maru TT, Kumalo A, Pandi-Perumal SR, Bahammam AS, Manzar MD. Validation of the Pittsburgh sleep quality index in community dwelling Ethiopian adults. Health and quality of life outcomes. 2017;15(1):1-7.

29. Berhanu H, Mossie A, Tadesse S, Geleta D. Prevalence and associated factors of sleep quality among adults in Jimma Town, Southwest Ethiopia: a community-based cross-sectional study. Sleep disorders. 2018;2018.

30. Gelaye B, Williams MA, Lemma S, Deyessa N, Bahretibeb Y, Shibre T, et al. Validity of the patient health questionnaire-9 for depression screening and diagnosis in East Africa. Psychiatry research. 2013;210(2):653-61.

31. Abate TWg. Medication non-adherence and associated factors among diabetes patients in Felege Hiwot Referral Hospital, Bahir Dar city administration, Northwest Ethiopia. BMC research notes. 2019;12:1-6.

32. Craig CL, Marshall AL, Sjöström M, Bauman AE, Booth ML, Ainsworth BE, et al. International physical activity questionnaire: 12-country reliability and validity. Medicine \& science in sports \& exercise. 2003;35(8):1381-95.

33. Muche AA, Olayemi 00, Gete YK. Prevalence of gestational diabetes mellitus and associated factors among women attending antenatal care at Gondar town public health facilities, Northwest Ethiopia. BMC pregnancy and childbirth. 2019;19(1):334. 
34. Saunders JB, Aasland OG, Babor TF, De la Fuente JR, Grant M. Development of the alcohol use disorders identification test (AUDIT): WHO collaborative project on early detection of persons with harmful alcohol consumption-II. Addiction. 1993;88(6):791-804.

35. Zewdu S, Hanlon C, Fekadu A, Medhin G, Teferra S. Treatment gap, help-seeking, stigma and magnitude of alcohol use disorder in rural Ethiopia. Substance abuse treatment, prevention, and policy. 2019;14(1):1-10.

36. Khalil M, Power N, Graham E, Deschênes SS, Schmitz N. The association between sleep and diabetes outcomes-A systematic review. Diabetes research and clinical practice. 2020;161:108035.

37. Gupta S, Wang Z. Predictors of sleep disorders among patients with type 2 diabetes mellitus. Diabetes \& Metabolic Syndrome: Clinical Research \& Reviews. 2016;10(4):213-20.

38. Htut HN, Howteerakul N, Suwannapong N, Rawdaree P. Sleep quality among type 2 diabetes mellitus patients in a private hospital setting in Yangon, Myanmar. Journal of Health Research. 2020.

39. Birhanu TT, Salih MH, Abate HK. Sleep Quality and Associated Factors Among Diabetes Mellitus Patients in a Follow-Up Clinic at the University of Gondar Comprehensive Specialized Hospital in Gondar, Northwest Ethiopia: A Cross-Sectional Study. Diabetes, metabolic syndrome and obesity: targets and therapy. 2020;13:4859.

40. Merin N, Antony R. Quality of Sleep among Diabetes and Non-Diabetes-Pilot Study. Indian Journal of Public Health Research \& Development. 2020;11(3).

41. Demir M. Quality of life and sleep in diabetes mellitus patients. 2019.

42. Ramtahal R, Khan C, Maharaj-Khan K, Nallamothu S, Hinds A, Dhanoo A, et al. Prevalence of selfreported sleep duration and sleep habits in type 2 diabetes patients in South Trinidad. Journal of epidemiology and global health. 2015;5(4):S35-S43.

43. Darraj A, Mahfouz MS, Alsabaani A, Sani M, Alameer A. Assessment of sleep quality and its predictors among patients with diabetes in Jazan, Saudi Arabia. Diabetes, metabolic syndrome and obesity: targets and therapy. 2018;11:523.

44. Bruehl H, Rueger M, Dziobek I, Sweat V, Tirsi A, Javier E, et al. Hypothalamic-pituitary-adrenal axis dysregulation and memory impairments in type 2 diabetes. The Journal of Clinical Endocrinology \& Metabolism. 2007;92(7):2439-45.

45. Almaiman AS, Alaqeel SS, Almuaili HA, Alaqil AS, Alghawi GA. Evaluation of sleep quality in Saudi Arabian patients with diabetes and hypertension. Age.20(39):40-59.

46. Shamshirgaran SM, Ataei J, Malek A, Iranparvar-Alamdari M, Aminisani N. Quality of sleep and its determinants among people with type 2 diabetes mellitus in Northwest of Iran. World journal of diabetes. 2017;8(7):358.

47. Cunha MCBd, Zanetti ML, Hass VJ. Sleep quality in type 2 diabetics. Revista latino-americana de enfermagem. 2008;16(5):850-5.

48. Nathan DM. Long-term complications of diabetes mellitus. New England Journal of Medicine. 1993;328(23):1676-85. 
49. Wakefield JR, Bowe M, Kellezi B, Butcher A, Groeger JA. Longitudinal associations between family identification, loneliness, depression, and sleep quality. British Journal of Health Psychology. 2020;25(1):1-16.

50. Zhang P, Lou P, Chang G, Chen P, Zhang L, Li T, et al. Combined effects of sleep quality and depression on quality of life in patients with type 2 diabetes. BMC family practice. 2016;17(1):1-7.

51. Wang C, Liu J, Li Z, Ji L, Wang R, Song H, et al. Predictor of sleep difficulty among community dwelling older populations in 2 African settings. Medicine. 2019;98(47).

52. Fang H, Tu S, Sheng J, Shao A. Depression in sleep disturbance: a review on a bidirectional relationship, mechanisms and treatment. Journal of cellular and molecular medicine. 2019;23(4):2324-32.

53. Rakel RE. Depression. Primary care. 1999;26(2):211-24.

54. Talbot F, Nouwen A. A review of the relationship between depression and diabetes in adults: is there a link? Diabetes care. 2000;23(10):1556-62.

55. Lustman PJ, Griffith LS, Gavard JA, Clouse RE. Depression in adults with diabetes. Diabetes care. 1992;15(11):1631-9.

56. Wang F, Boros S. The effect of physical activity on sleep quality: a systematic review. European Journal of Physiotherapy. 2021;23(1):11-8.

57. Buman MP, Phillips BA, Youngstedt SD, Kline CE, Hirshkowitz M. Does nighttime exercise really disturb sleep? Results from the 2013 National Sleep Foundation Sleep in America Poll. Sleep Medicine. 2014;15(7):755-61.

58. Thomas D, Elliott EJ, Naughton GA. Exercise for type 2 diabetes mellitus. Cochrane database of systematic reviews. 2006(3).

59. Patel PN, Zwibel H. Physiology, Exercise. StatPearls. Treasure Island (FL): StatPearls Publishing Copyright (C) 2021, StatPearls Publishing LLC.; 2021.

60. Yoda K, Inaba M, Hamamoto K, Yoda M, Tsuda A, Mori K, et al. Association between poor glycemic control, impaired sleep quality, and increased arterial thickening in type 2 diabetic patients. PloS one. 2015;10(4):e0122521.

61. Al Hayek AA, Al Dawish MA. Clinical and psychological characteristics of liraglutide treatment among patients with type 2 diabetes. Journal of family medicine and primary care. 2020;9(2):1065.

62. Amelia R, Harahap J, Harahap NS, Wijaya H, Ariga RA, Fujiati II, et al. Effect of Sleep Quality on Blood Glucose Level of Type 2 Diabetes Mellitus Patients in Medan, Indonesia. Open Access Macedonian Journal of Medical Sciences. 2020;8(E):574-7.

63. Chung J. Social support, social strain, sleep quality, and actigraphic sleep characteristics: evidence from a national survey of US adults. Sleep health. 2017;3(1):22-7.

64. Mesas AE, Peppard PE, Hale L, Friedman EM, Nieto FJ, Hagen EW. Individuals' perceptions of social support from family and friends are associated with lower risk of sleep complaints and short sleep duration. Sleep health. 2020;6(1):110-6. 
65. Riahi M, Aliverdinia A, Pourhossein Z. Relationship between social support and mental health. Social Welfare Quarterly. 2011;10(39):85-121.

66. Harandi TF, Taghinasab MM, Nayeri TD. The correlation of social support with mental health: A metaanalysis. Electronic physician. 2017;9(9):5212.

67. Turner RJ, Brown RL. Social support and mental health. A handbook for the study of mental health: Social contexts, theories, and systems. 2010;2:200-12.

68. Leggett A, Assari S, Burgard S, Zivin K. The effect of sleep disturbance on the association between chronic medical conditions and depressive symptoms over time. Longitudinal and life course studies. 2017;8(2):138. 